\title{
Positive outcomes of Cure and Care Community Centres (CCSC): a community based treatment programme in Malaysia
}

\author{
Mahmood Nazar Mohamed, Sabitha Marican. \\ Cyberjaya University College of Medical Sciences and Universiti Malaya. \\ Correspondence: email: mahmoodnazar@gmail.com
}

\begin{abstract}
In an effort to depart from the Compulsory Centre for Drug Users (CCDU), Malaysia has initiated the Cure and Care Service Centre (CCSC) programme to provide a community based treatment programme that provides a multitude of services related to drug and substance abuse rehabilitation to drug users, dependents and recovering persons. The objective of this study is to identify the outcomes of the CCSC service. The population of this study is the clients of CCSCs during the period of its operation (2011-2012).
\end{abstract}

Ten CCSCs were randomly chosen with reference to their location in the four zones (North, South, East and Central) in the Malaysia Peninsular. A total of 232 clients responded to the study. The study found that the outcome of drug rehabilitation programmes at CCSCs was generally positive. The main outcome was that clients' involvement in criminal activities had reduced significantly after they had completed their CCSC programmes. The consumption of ketum leaves extracts, alcohol, drugs and even drug injecting behaviour had also reduced significantly. Almost $20 \%$ of the clients gained employment after being discharged from the programme. Also about one third of the clients have changed their lifestyles: they took care of their health, engaged in physical activities and exercises; played sports; took their medicine and relaxed sufficiently. Some were involved in religious activities, and almost half were seen to have made that change. Around $20 \%$ has started to renew relationships with their parents, siblings and other family members. A smaller number got involved in intimate relationships and even marriage. Many clients managed to obtain more permanent jobs, engaged in recreational sports activities and enhanced relationships with their families. Overall the outcome of the CCSC programme was successful.

Keywords: Cure and care community centres, Community based treatment, drug and substance abuse rehabilitation, Malaysia

\section{Introduction}

The existence of drug addiction treatment centres, especially the Compulsory 
Centres for Drug Users (CCDUs), has been observed in many countries since the onset of the drug problem in the Asia. ${ }^{1}$ In Southeast Asian countries, there are various forms of CCDUs such as drug treatment centres, drug detention centres, drug prisons and many more. Often the 'boot camp' model is used, with emphasis on discipline, religious values and socially acceptable behaviour. Drug users mandated for drug treatment were often labelled as inmates. Little medical attention was given to these 'inmates', and many contracted communicable diseases such as hepatitis, STIs, HIV, tuberculosis as a result of their drug use, drug injection, multiple sexual partners, poor living conditions and tight living quarters in detention centres. . $^{2,19}$

At present, over 300,000 men, women and children suspected of using drugs are detained in some 1,000 CCDUs in East and South East Asia alone., ${ }^{1,7}$ Such a large number of drug dependents were registered at CCDUs because most often they were legally mandated by drug (or anti-drug) laws in their country.

Almost all CCDUs are free. Some may require parents or significant others to pay a minimal fee for treatment and rehabilitation as compared to receiving treatment in hospitals and voluntary units or private treatment centres. As a point of cost comparison, in Malaysia, treatment at private centres costs between USD 300 to 3,000; in Indonesia it is between USD 250 to 5,000; in the Philippines it is between USD 600 to 8,000 and Thailand it is between USD 500 to 5,000 as compared to government CCDUs which are generally free of charge. ${ }^{3}$

Many CCDUs have infringed on the human rights of drug addicts undergoing treatment. 2,4,5,6,19 The detention of people in such centres has also been reported to involve a range of other measures that violate human rights, including sub-standard conditions, forced labour, physical and sexual violence and lack of access to healthcare, including HIV prevention services, among others. ${ }^{1,4,5,6}$ In addition, the non-evidenced treatment practices left no positive outcomes to people receiving treatment. This issue was highlighted by $12 \mathrm{UN}$ agencies in 2012, and among others included increased vulnerability to HIV and tuberculosis infection as well as insufficient legal safeguards and judicial review. As an alternative to compulsory drug detention and rehabilitation centres, the UN agencies advocated for states to make available voluntary, evidence-informed and rights-based health and social services in the community.,1,19

Community-Based Treatment (CBT) and Cure and Care Service Centre (CCSC)

The International Network of Drug Treatment and Rehabilitation Resource Centre $^{8}$ defines community based drug treatment as an integrated model of 
treatment in the community. It includes services from detoxification to aftercare and also involves the coordination of any number of non-specialist services that are needed to meet clients' needs. A key focus of community based treatment is on reaching people that are affected by the harms of substance abuse with limited access to services. Integrate drug treatment and rehabilitation programmes into the community health and social services; community participation; and sustainability and accountability to the community.

One pertinent issue faced by Asian countries is the well-established drug control laws and emerging drug laws for mandatory treatment and rehabilitation. ${ }^{19}$ The same situation is faced in Malaysia. However, the government has set up an innovative project to harmonise between the country's drug laws, addressing CCDUs and human rights issues. ${ }^{9}$ The Cure and Care (C\&C) project was established in 2010 in response to low treatment outcomes such as high-relapse rates, poor re-employment capacities and re-engagement to criminal behaviour associated with CCDUs. Here, the government, through the National Anti-Drug Agency (NADA) began to gradually move away from CCDUs and introduced a number of evidence and Community-Based Treatment (CBT) services for illicit drug users. Since then, Malaysia has made considerable progress in the provision of voluntary drug treatment and rehabilitation. ${ }^{7,9}$

The statistics related to mandatory treatment in Malaysia is also evident to these new initiatives. The number of drug addicts caught under the Drug Dependent Act (Treatment and Rehabilitation) (DDA) of 1983 peaked at 38,672 in 2004. At the time, drug treatment and rehabilitation was mostly conducted at government CCDUs, also known as 'Pusat Serenti' for a period of not less than two years. Voluntary treatment centres were then still very limited, and many did not practice evidence-based drug treatment. In 2008, the government permitted the prescription of MMT by private medical practitioners for treatment of opiate dependents. Many came forward to pay for the treatment, ranging between USD 10 to 25 per treatment. In addition, the Ministry of Health also dispensed free methadone through NADA. As a result, the number of drug dependents arrested in 2010 decreased to 23,642. Then, in 2010, the Malaysian Government initiated the Cure and Care Project and the number arrested in 2011 and 2012 reduced to 11,154 and 9,015 cases respectively.,10

The first Malaysian CBT is the Cure and Care Service Centre (CCSC) that was established in the drug-stricken area of Chow Kit, in Kuala Lumpur. CCSC also functions as an outreach centre, providing counselling, medical check-ups, psychosocial programmes, methadone maintenance therapy, spiritual and moral education, and support for integration. About 100-150 clients visited the Chow Kit CCSC daily; and over a period of one year, more than 200 were referred to 
C\&C clinics for treatment, and more than 500 were referred to the methadone programme at hospitals in Kuala Lumpur. Additional NGO-operated CCSCs were also set up in the city of Ipoh and in rural Jengka Pahang to address many drug dependents and IDUs that needed access to such services.?

The CCSC programme was modelled on the Outpatient Drug-Free (ODF) programme. Flynn et al. stated that ODF "...is characterised by a wide range of therapeutic approaches such as cognitive-behavioural, insight-oriented, supportive and 12-steps," to provide treatment and rehabilitation services to people dependent on drugs and other substances. ${ }^{11}$

CCSC also used the Short-Term In-patient (STI) model where clients can stay in for up to 30 days. It also employed the halfway house and drop-in-centre model for clients who preferred to drop in for meals, to wash and bathe, and get medical treatment.

At CCSC, clients are evaluated by using the Alcohol, Smoking and Substance Involvement Screening Test (ASSIST); they are grouped by their addiction or the substance use severity scores they have obtained i.e. low, medium and high. Their initial intervention programme at the CCSC is guided by this score. For example, those obtaining a low severity score (0-3) are given counseling and guidance (three sessions); self management skills (three sessions); and the early recovery package (one session). ${ }^{10}$

Clients with moderate ASSIST scores (4-26) get guidance and counseling (six sessions); relapse prevention (six sessions); support group (12 sessions); family development (six sessions); self management skills (three sessions); moral and religious programme (12 sessions); outing and recreation (three sessions); and social integration (three sessions). If the client requires Methadone Maintenance Treatment (MMT), they face a medical assessment before being put into this long term programme. ${ }^{10}$

Clients who score high on ASSIST get guidance and counselling (12 sessions); relapse prevention (12 sessions); support group (12 sessions); family development (12 sessions); self management skills (12 sessions); moral and religious programme (12 sessions); sports and recreation (12 sessions); health education (three sessions); and social integration (three sessions). Similarly, if the client requires MMT, they face another medical assessment before being put into this long term programme. Upon completing the stay-in programme, they join the day visit group to continue their rehabilitation programme. ${ }^{10}$

Under these initiatives, the Malaysian Government did not change any of its drug laws. The DDA of 1983 is still being used to arrest drug addicts, but as shown in the above statistics, the number has reduced over the years. The current 
UNODC-endorsed CBT initiatives operate within the existing legal framework and have developed an open system with community based services and comprehensive inter-agency collaboration. This is one of the drug treatment and rehabilitation models in Asian countries acknowledged by UNODC to be considered as applicable in countries with strict drug laws, but with much interest in human rights and public health. ${ }^{7}$

But there are questions about the effectiveness of the CCSC programme. Is it effective? What is the outcome of the programme? Are drug users and addicts who accessed its services referred to a more elaborated treatment programmes if needed? Can they be re-integrated into society? This study will provide some answers to these questions on the outcomes of the CCSC programme after more than two years in operation.

\section{Objective}

The objective of this study is to identify the outcomes of the CCSC programme with specific reference to using illicit drugs and substances; engagement in criminal activities; taking care of one's health; changes in lifestyle; employment status; social reintergration; religious and spiritual activities; and establishing relationships and marriage.

\section{Methodology}

This study adopts a cross-sectional survey method using structured interviews to ascertain data pertaining to the effectiveness of the CCSC programme. The population of the study is clients who have accessed the services provided by CCSC throughout its operation from 2011 to 2012. A total of 10 CCSCs were selected for this purpose. Each sampled CCSC provided researchers with a list of clients that have accessed their service from 2011 to 2012. Clients were chosen among those who have access to services for at least six months prior to the interview. About 30 clients were randomly sampled from each list from the selected CCSC. The number of clients involved in the study is shown in Table 1.

These clients were interviewed by the researchers based on outcome indicators as listed in Table 3. These indicators were compiled from expected outcomes of drug treatment and rehabilitation programmes stated by the WHO and UNODC. ${ }^{12,13,14,15}$ They are drug and substance use, alcohol consumption, health related behaviour (visits to doctors, general health care); social indicators (improving family relations, social involvement); career and employment (part-time and full time employment, income); involvement in religious practice and involvement in criminal activities. ${ }^{12,13,14,15}$

The interviews were conducted on a one-on-one basis. The interviewers intro- 
duced themselves and the purpose of the study. There were ice-breaking sessions with the respondents before the first question was asked. The interviewers reported positive sessions with the respondents, and noted that none had disagreed to answer any questions. The interviews lasted between 15 to 20 minutes.

Table 1. Number of clients at the participating CCSC

\begin{tabular}{|llll|}
\hline No & CCSC & N & $\%$ \\
\hline $\mathbf{1}$ & Bandaraya Ipoh, Perak & 30 & 9.3 \\
$\mathbf{2}$ & Kg. Selamat, SP Utara & 30 & 9.3 \\
$\mathbf{3}$ & Kuala Terengganu, Trg & 30 & 9.3 \\
$\mathbf{5}$ & Muar, Johor & 30 & 9.3 \\
$\mathbf{6}$ & Telok Bahang, P.Pinang & 30 & 9.3 \\
$\mathbf{7}$ & Dang Wangi, KL & 30 & 9.3 \\
$\mathbf{8}$ & Seremban, NS. & 48 & 14.9 \\
$\mathbf{9}$ & Jengka, Pahang & 30 & 9.3 \\
$\mathbf{1 0}$ & Chow Kit, KL & 30 & 9.3 \\
Total & & 35 & 10.7 \\
\hline
\end{tabular}

A range of 30 to 48 clients were identified from the CCSCs participating in this study; 232 respondents provided information and feedback pertaining to their activities and situations prior to gaining access to services provided by the CCSC, and after having gone through programmes at CCSC (Table 1). Most of the clients who accessed the CCSC's services were volunteers $(n=240)$. Only about $25 \%$ were mandated by the criminal justice system. About $50 \%$ were stay-in clients at the CCSC (Table 2).

Table 2. Types of services provided to clients by CCSC

\begin{tabular}{|llc|}
\hline Services & Frequency & $\%$ \\
Day Drop in & 105 & 32.7 \\
Stay In & 164 & 50.8 \\
MMT & 53 & 16.5 \\
Total & $\mathbf{3 2 2}$ & $\mathbf{1 0 0}$ \\
\hline
\end{tabular}




\section{Result}

The results are shown in Table 4. A total of nine indicators were used i.e. drug and substance use (five items); health care (five items); employment (three items); familial relations (two items); intimate relationships (two items); societal involvement (one item); religious involvement (two items); self development (three items) an legal (one item) (Table 3).

It was observed that drug and substance use had reduced across the board; 316 respondents used drugs before they entered the CCSC and only 10 respondents said they still used drugs after obtaining services from the CCSC. Despite using illicit substances, respondents told interviewers that the quantity had reduced because they wanted to undergo the full treatment. For drug injectors, the number involved had reduced from 185 to 23 persons; consuming alcohol also reduced from 192 to 36 persons; drinking ketum reduced from 100 to 17 and those involved in glue or inhalant sniffing also reduced drastically from 50 to zero.

The second indicator is healthcare. The study found that there is an increase in the number of respondents using methadone, from 152 to the present 197 clients. The number of respondents who consulted doctors for health reasons also increased from 152 before coming to the CCSC, to 197 after following the CCSC programme. Similarly those who took medication for their illnesses increased from 134 to 282. Respondents who started healthy lifestyles also increased from 110 to 282. These findings indicate that between 20 to 35\% of respondents practiced a healthier lifestyle after attending the CCSC programmes. 
Table 3. Outcomes of CCSC

\begin{tabular}{|c|c|c|c|c|c|}
\hline \multirow[t]{2}{*}{ No } & \multirow[t]{2}{*}{ Measures } & \multicolumn{2}{|c|}{ Before CCSC } & \multicolumn{2}{|c|}{ After CCSC } \\
\hline & & (n) & $(\%)$ & (n) & $(\%)$ \\
\hline 1 & $\begin{array}{l}\text { Using drugs (Amphetamine type } \\
\text { stimulants or ATS, Heroin, Morphine, } \\
\text { Ganja, Psychoactive Pills) }\end{array}$ & 316 & 99.4 & 103 & 32.5 \\
\hline 2 & Injecting drugs & 185 & 57.6 & 23 & 7.4 \\
\hline 3 & Alcohol consumption & 192 & 60.0 & 36 & 11.7 \\
\hline 4 & Using inhalants & 50 & 15.6 & 0 & 0.0 \\
\hline 5 & $\begin{array}{l}\text { Consuming ketum leaves } \\
\text { (mitragynine } \mathrm{sp} \text { ) }\end{array}$ & 100 & 31.3 & 17 & 5.7 \\
\hline 6 & Methadone/subutex / subuxone & 152 & 47.4 & 197 & 62.7 \\
\hline 7 & Consulting doctors to identify illness & 150 & 46.7 & 244 & 76.5 \\
\hline 8 & Taking medication for illness & 125 & 39.2 & 206 & 64.6 \\
\hline 9 & General healthcare & 134 & 42.1 & 282 & 89.2 \\
\hline 10 & Exercise for health & 110 & 34.4 & 232 & 73.2 \\
\hline 11 & Part-time job & 186 & 57.9 & 151 & 48.2 \\
\hline 12 & Permanent job & 90 & 28.3 & 141 & 44.9 \\
\hline 13 & Increase in monthly income & 140 & 43.3 & 167 & 51.7 \\
\hline 14 & Maintaining positive relationships with & 187 & 58.6 & 235 & 76.3 \\
\hline
\end{tabular}




\begin{tabular}{|c|c|c|c|c|c|}
\hline \multirow[t]{2}{*}{ No } & \multirow[t]{2}{*}{ Measures } & \multicolumn{2}{|c|}{ Before CCSC } & \multicolumn{2}{|c|}{ After CCSC } \\
\hline & & (n) & $(\%)$ & (n) & $(\%)$ \\
\hline & parents & & & & \\
\hline 15 & $\begin{array}{l}\text { Maintaining positive relationships with } \\
\text { siblings and other family members }\end{array}$ & 206 & 64.8 & 266 & 83.4 \\
\hline 16 & Engaging in intimate relationship & 157 & 49.4 & 107 & 33.8 \\
\hline 17 & Marriage & 107 & 33.4 & 80 & 25.3 \\
\hline 18 & Involvement in societal activities & 160 & 50.3 & 260 & 81.3 \\
\hline 19 & Praying & 139 & 43.7 & 289 & 90.6 \\
\hline 20 & Practicing the teachings of your religion & 112 & 35.1 & 236 & 74.0 \\
\hline 21 & Engaging in sports & 112 & 35.2 & 196 & 61.4 \\
\hline 22 & Recreational activities & 128 & 40.1 & 224 & 70.4 \\
\hline 23 & Study for self development & 90 & 28.1 & 167 & 52.4 \\
\hline 24 & Involvement in criminal activities & 186 & 58.1 & 23 & 7.2 \\
\hline
\end{tabular}


Regarding employment, a small amount, about 20\% managed to gain employment after following the CCSC programme. This is a positive indicator because drug addicts in Malaysia have over the years, faced the issue of unemployment after their treatment programme. ${ }^{17}$ This study observed that the numbers involved in part-time employment reduced from $57.9 \%$ to $48.2 \%$ whereas a larger number gained permanent employment, from 90 to 141. As a result, more clients reported an increase in their monthly income.

The next outcome indicator is positive relationships with others. There as an increase of $17.7 \%$ respondents reporting that they have and maintain positive relationships with their parents; and $18.6 \%$ reported positive relations with their siblings and other family members. However, respondents who started to engage in intimate relationships reduced from $49.7 \%$ to $33.8 \%$, and those who marry also reduced from $33.4 \%$ to $25.3 \%$. Interestingly, during the interview sessions, respondents informed the researchers that they were trying to gain better employment before planning a family.

One of the programmes at the CCSC is to re-integrate clients into society. This yielded positive results as more respondents said they were involved in societal activities. Some of these were religious activities at the local surau or mosque. This is in line with respondents' increased involvement with religious activities; $47 \%$ said they had started to pray; and those who practice the teachings of their religion increased from $35.1 \%$ to $74 \%$.

Other indicators were clients' engagement in sports, recreational activities and study for self development, all of which saw an increase after they participated in the CCSC programme. But one of the biggest differences was that less numbers were involved in criminal activities ranging from petty theft to drug peddling. A total 186 clients reported involvement in crime before CCSC, and after going through the programme, the number decreased to 23 , which is a reduction of $50.9 \%$.

\section{Discussion}

The CCSC programme is one of the innovative approaches introduced by the Malaysian Government to attract more clients among people who use illicit drugs and substances to seek voluntary drug treatment and rehabilitation in their community. ${ }^{10}$ Malaysia is known for its very stringent drug laws. The Dangerous Drugs Act (1952) imposed a mandatory death sentence on drug traffickers for carrying as little as 15 grammes of heroin or morphine; 40 grammes of cocaine; 200 grammes of cannabis; 2000 grammes of coca leaves or 50 grammes of ATS. There have been several international reactions towards this capital punishment imposed on traffickers. However such strict laws not only exist in Malaysia but in many other Asian countries. ${ }^{7}$ 
In 1983, the DDA was passed, allowing authorities to bring any person addicted to drugs to a mandatory treatment programme set up by the government for a period of not more than two years in the Serenti Drug Treatment Centres and another additional two years in the community.

Furthermore, the DDA (Revised 2002) (A1167) also imposes severe punishment on drug addicts and repeated offenders. Drug addicts who relapse and use drugs after going through the Serenti Government Rehabilitation Programme twice are imprisoned for three to five years and caned not more than three times. If they relapse a fourth time, they can be imprisoned for seven to 13 years and caned between three to six times.

In the past, many drug addicts have had to undergo mandatory treatment under these Acts. Relapse is high and this can be seen as soon as the offenders leave the Serenti CCDUs. Even the community based treatment that follows the two year treatment programme in the institution is not deemed effective. ${ }^{7}$ The drug treatment programme seems to be collapsing under its own weight.

However, after drug addiction was declared by the WHO as a relapsing disease, Malaysia has made significant changes to its approach in treating drug offenders. More voluntary programmes were erected, replacing many mandatory treatment centres. The Cure and Care programme that started in 2010 has attracted many international visitors. This was because Malaysia did not change any of its drug laws, but adopted a policy shift towards evidence-based treatment. Also MMT and other opiate substitution treatments were placed by the Malaysian Ministry of Health. As a result, many drug addicts surfaced, seeking voluntary treatment and the free MMT that is provided by the government. Since then, the number of drug addicts arrested reduced drastically.

This study demonstrates the positive outcome of the CBT called the CCSC. Over a short period of time, clients of the CCSC have reduce their drug use, do not inject drugs, practice a healthier lifestyle and avoid criminal activities. The views of the public were also positive, with many wanting to know how successful the C\&C programme was. Clients reported a higher level of satisfaction towards the services provided by the CCSC and did not feel they were being sanctioned by society. As a result, businesses are taking chances to offer employment for recovering addicts with better terms and conditions and income. ${ }^{16,17}$ Thus, an entire process of positivity is taking place within the drug addict community with the CCSC programme, and this brings hope for more positive results in the near future. 


\section{References}

1. UNODC. (2012). UN calls to close compulsory drug detention and rehabilitation centres without delay [Internet]. 2012b March 9 [Cited 2013 Nov 30]: Available from: http://www.unodc.org/southeastasiaandpacific/en/2012/03/detention-centres/story.html.

2. Fu JJ, Bazazi AR, Altice FL, Mohamed MN, Kamarulzaman A. Absence of antiretroviral therapy and other risk factors for morbidity and mortality in Malaysian compulsory drug detention and rehabilitation centres. PLoS ONE [Internet]. 2012 [Cited 2013;7(9). e44249.

Doi: http://dx.doi.org/10.1371/journal.pone.0044249

3. Mahmood NM, Yahya D, Dzahir MK. The practice of TC in 5 ASEAN Countries, Paper presented at the XXIII World Federation of Therapeutic Community Conference, New York, NY: 2006 September 1-5.

4. UNODC. Where darkness knows no limits: Incarceration, ill-treatment and force labor as drug rehabilitation in China [Internet]. 2010a January [Cited 2013 Nov 25]: Available from: http://www.hrw.org/reports/2010/01/07/where-darkness-knows-nolimits-0.

5. UNODC Track on compulsory drug dependence treatment centres: Second Asian consultation on the prevention of HIV related to drug use. 2010b January 21? 23; Bangkok Thailand.

6. UNODC. The rehab archipelago: Forced labor and other abuses in drug detention centres in southern Vietnam [Internet]. 2011 September [Cited 2013 Nov 28]: Available from: http://www.hrw.org/reports/2011/09/07/rehab-archipelago-0.

7. UNODC. Drug Demand Reduction. Southeast Asia and the Pacific [Internet]. 2013 [Cited 2013 Nov 29]: Available from: http://www.unodc.org/southeastasiaandpacific/en/topics/drug-demandeduction/index.html

8. Treat Net (2006). Community base treatment [Internet]. 2006 [Cited 2013 Nov 30]: Available from: http://www.unodc.org/treatment/en/community_based_treatment.html

9. Mahmood NM. Drug situation in Malaysia: Trends, incidences and anti-drug strategies. Indian J Psychol, 2012a; 71-82.

10. NADA. (2013). NADA Annual Report [Internet]. 2013 [Cited 2013 Nov 30]; Available from: www.adk.gov.my 
11. Flynn PM, Craddock SG, Hubbard RL, Anderson J, Etheridge RM. Methodological overview and research design for the Drug Abuse Treatment Outcome Study (DATOS). Psychol Addict Behav. 1997;11(4):230-43.

Doi: http://dx.doi.org/10.1037/0893-164X.11.4.230

12. Hubbard RL, Craddock SG, Flynn PM, Anderson J, Etheridge RM. Overview of 1-year follow-up outcomes in the Drug Abuse Treatment Outcome Study (DATOS). Psychol Addict Behav, 1997;11(4): 261278.

Doi: http://dx.doi.org/10.1037/0893-164X.11.4.261

13. Simpson DD, Curry SJ. (Eds.). Special Issue: Drug Abuse Treatment Outcome Study (DATOS). Psychol Addict Behav, 1997;11(4).

14. Simpson DD, Joe GW, Fletcher BW, Hubbard RL, Anglin MD. A national evaluation of treatment outcomes for cocaine dependence. Arch Gen Psychiatry 1999;56:507-s14.

Doi: http://dx.doi.org/10.1001/archpsyc.56.6.507

15. Simpson DD. Brown B. (Eds.). Special issue: Treatment process and outcome studies from DATOS. Drug Alcohol Dependence, 1999;57(2).

16. Mahmood NM. Policy and tolerance towards drug use and abuse among Malaysian organization. Int J Management Stud, 2006;4:67-78.

17. Mahmood NM. Are our organizations willing to help 'ex-junkie to be employed? Inputs for employment policy for recovering drug users in Malaysia. Malays J Psychol Public Service Counseling, 2012b;7:3245.

18. Tongue E, Turner D. Treatment options in responding to drug misuse problems. ONDCP Bull Narcotics Issue 1-001. 1988

19. Noor Zurina MR, Rusdi AR, Mahmood NM, Habil H Treating heroin addiction: Bridging the past and future. A Malaysian experience, Asia Pac Psychiatry [Internet]. 2012 Apr [Cited 2013 Nov 30];

Doi: http://dx.doi.org/10.1111/j.1758-5872.2012.00194.x

20. Yahya D. Mahmood NM. Hubungan Jenayah dengan Penagihan dadah, Jurnal PSIMA (Malays J Psychol). 2002;16:56-74. 